\title{
Para além do Édipo: entre Deleuze-Guattari e Laplanche
}

\author{
Vinícius Moreira Lima, ${ }^{(\mathbb{D})}$ Heloísa Moura Bedê \\ Universidade Federal de Minas Gerais, Belo Horizonte, MG, Brasil
}

\section{Resumo}

O objetivo deste artigo é analisar as maneiras pelas quais o complexo de Édipo foi reelaborado nas formulações de Gilles Deleuze e Félix Guattari, bem como de Jean Laplanche. Tentamos mostrar que as formulações laplancheanas permitem responder a algumas das críticas levantadas pelos autores de O anti-Édipo. Tanto para Laplanche quanto para Deleuze e Guattari, o que está em questão é retomar o que cada um considera como a originalidade da descoberta freudiana: a prioridade do Sexual, no caso do psicanalista, e a prioridade do sexo não humano, no caso dos esquizoanalistas. Após apresentar os principais fundamentos de cada corrente, promovemos uma reflexão sobre as ligações entre o Édipo e as questões de gênero a partir das obras desses autores. Recorrendo também às contribuições de Judith Butler para esse debate, levantamos a hipótese de que as normas de gênero, ao instituírem um sexo binário, servem como suporte para a repressão e o recalque do Sexual e do sexo não humano, que desprezam o binário normativo homem-mulher ou papai-mamãe. Como resultado, acreditamos apontar, com Laplanche e as contribuições da esquizoanálise, para a possibilidade de uma psicanálise pós-edipiana ou, até mesmo, não edipiana.

Palavras-chave: desejo; Édipo; inconsciente; psicanálise; sexualidade.

\section{Beyond Oedipus: between Deleuze-Guattari and Laplanche}

\begin{abstract}
This article aims to analyze the ways in which the Oedipus complex has been reworked in the formulations of Gilles Deleuze and Félix Guattari, as well as of Jean Laplanche. We tried to show that Laplanchean psychoanalysis allows us to respond to some of the critics made by the authors of The Anti-Oedipus. For Laplanche, as well as for Deleuze and Guattari, what is at stake is in what consists the originality of the Freudian discovery for each one: the priority of the sexual, to the psychoanalyst, and the priority of the non-human sex, to the schizoanalysts. After presenting the fundaments of each current, we promote a reflection on relations between Oedipus and gender based on the works of these authors. Also recurring to the contributions of Judith Butler to this debate, we hypothesize that gender norms, while instituting binary sex, serve as a support for the repression (meaning both "Unterdruckung" and "Verdrangung") of the sexual and of non-human sex, who despise the normative binary of man-woman. Thus, we believe it was possible to point, along with Laplanche and the contributions of schizoanalysis, to a post-Oedipal or even a non-Oedipal psychoanalysis.
\end{abstract}

Keywords: desire; Oedipus; unconscious; psychoanalysis; sexuality.

\section{Introdução}

No Vocabulário da psicanálise (LAPLANCHE; PONTALIS, 2016, p. 77), o complexo de Édipo é definido como conjunto "organizado de desejos amorosos e hostis que a criança sente em relação aos pais". Ele se apresenta sob uma forma dita "positiva" - em que a criança deseja a morte do progenitor do mesmo sexo e tem desejo sexual pelo progenitor do sexo oposto - e sob uma forma dita "negativa": amor pelo progenitor do mesmo sexo e ódio ao progenitor do sexo oposto. Ambas estariam presentes na forma completa do complexo, em graus diversos, para todos os sujeitos. Mais adiante, lemos que o Édipo "desempenha papel fundamental na estruturação da personalidade e na orientação do desejo humano" (LAPLANCHE; PONTALIS, 2016, p. 77), de modo que, para os psicanalistas, "ele é o principal eixo de referência da psicopatologia; para cada tipo patológico eles procuram determinar as formas particulares da sua posição e da sua solução".

Dessa maneira, a estrutura triangular edipiana constituiria uma formação necessária para os sujeitos, independentemente das configurações familiares de cada

\footnotetext{
^Endereço para correspondência: Universidade Federal de Minas Gerais, Faculdade de Filosofia e Ciências Humanas. Avenida Presidente Antônio Carlos, 6627 - Pampulha - Belo Horizonte, MG - Brasil. CEP 31270-901. E-mails: vmlima6@gmail.com, heloisa.bede@gmail.com
}

Os dados completos dos autores encontram-se ao final do artigo. cultura. Esse postulado antropológico, por suas pretensões universalizantes, foi amplamente criticado por uma série de autores, entre eles, Jean Laplanche, Gilles Deleuze e Félix Guattari. No presente trabalho, tencionamos analisar as maneiras pelas quais o complexo de Édipo, conceito freudiano amplamente incorporado no pensamento psicanalítico, foi reelaborado nas formulações laplancheanas a partir das críticas que encontramos em $O$ anti-Édipo (DELEUZE; GUATTARI, 1972/2011). Isso implica questionar uma redução generalizada do desejo e do inconsciente ao Édipo, redução que aspira a uma genitalidade reprodutiva derivada de um modelo familiar normativo e devedor da modernidade ocidental.

Esse questionamento nos é franqueado pelo fato de que, na própria obra de Freud, a aparição do termo "complexo de Édipo" é tardia, surgindo apenas em um artigo de 1910 (cf. LAPLANCHE; PONTALIS, 2016). O que aponta para a possibilidade de uma psicanálise não restrita ao Édipo, possibilidade essa que, especialmente ao longo do século XX, foi bastante negligenciada. Assim, a importância das críticas de Laplanche e Deleuze-Guattari está, a nosso ver, em renovar o estatuto do inconsciente, na medida em que este descentra o sujeito pela primazia do outro e do socius em sua constituição psíquica. Buscamos, com o presente artigo, mostrar como, de certa maneira, as formulações laplancheanas permitem res- 
ponder a algumas das críticas levantadas pelos autores de O anti-Édipo (DELEUZE-GUATTARI, 1972/2011). Isso na medida em que ambas as teorizações buscam retomar a originalidade da descoberta freudiana: a prioridade do Sexual, do sexo não humano. Nosso objetivo, portanto, não é fazer críticas a Lacan, que é um alvo comum dos autores em questão. Antes, queremos apresentar propostas de Laplanche e da esquizoanálise que contornem a edipianização da psicanálise.

Empregamos aqui "Sexual", em vez de "sexual", de forma a acompanhar os tradutores da obra de Laplanche (2003/2015b). O "S" maiúsculo tem o intuito de preservar a distinção no original em francês entre sexuel e sexual, sem correlato na língua portuguesa. $\mathrm{O}$ primeiro termo refere-se ao uso comum do adjetivo sexual, e o segundo, a um neologismo do autor para conceber a sexualidade ampliada no sentido freudiano, isto é, sua dimensão infantil, que vai mais além de um inconsciente edipiano. Este conceito, o Sexual, objeto da psicanálise, é definido por Laplanche (2003/2015b, p. 140) como:

1) uma sexualidade que ultrapassa absolutamente o genital, ou mesmo a diferença sexuada; 2) uma sexualidade ligada à fantasia [fantasme]; 3) uma sexualidade extremamente móvel quanto à meta e ao objeto; e [...] 4) uma sexualidade que tem como regime "econômico", no sentido freudiano do termo, um regime de funcionamento próprio, ou seja, não sistematicamente a tendência à descarga, mas realmente a tendência ao aumento de tensão, à busca da excitação. Em suma, é a sexualidade à frente, ou além do sexo ou do sexuado.

Assim, apresentaremos, em primeiro lugar, algumas das propostas da esquizoanálise, seguidas dos trabalhos de Laplanche, para, finalmente, discutir suas aproximações e seus distanciamentos.

\section{O Édipo como repressão social em Deleuze e Guattari}

Em um seminário de 1973, Deleuze (2006, p. 345) afirma que a psicanálise é uma máquina interpretativa já pronta, automática, que impede as pessoas de falarem, uma vez que ela já "dispõe de um código pré-existente" que traduz em outra linguagem tudo que o paciente possa dizer. Código esse que é constituído por Édipo, pela castração e pelo romance familiar. Isso significa que a clínica psicanalítica operaria uma redução ideológica que "esmagaria" o desejo ao remetê-lo incessantemente às figuras edipianas. Em contraposição a essa edipianização furiosa, a esquizoanálise, proposta de Deleuze e Guattari (1972/2011, p. 135), pretende ser "uma psicanálise política e social, uma análise militante".

Tal movimento implicou rever alguns dos pressupostos psicanalíticos tradicionais, de maneira a possibilitar uma crítica à psicanálise como dispositivo de neurotização de sujeitos, um dispositivo que produziria sujeitos resignados, castrados, faltosos, em suma, edipianizados. Isso porque a tendência comum entre os analistas de meados do século XX, de acordo com Deleuze e Guattari (1972/2011, p. 94), era fazer remeter ao Édipo do analisando todas as questões trazidas por ele ao consultório: "Suspiro de alívio: veja, o coronel, o instrutor, o professor, o patrão, tudo isto queria dizer isso, Édipo e a castração".
Mas, como os autores apontam, não foi a psicanálise que inventou Édipo; antes dela já existia a repressão social. "Tudo mostra o contrário: os sujeitos já chegam edipianizados à psicanálise, eles pedem e tornam a pedir isso mesmo" (DELEUZE; GUATTARI, 1972/2011, p. 164), de maneira que o desejo busca sua própria repressão, edipianamente. E isso é transmitido desde o ambiente familiar ele mesmo, na medida em que, antes de ser um sentimento de neurótico, "Édipo é uma ideia de paranoico adulto" (DELEUZE; GUATTARI, 1972/2011, p. 362). Dito de outro modo, é o pai paranoico que edipianiza o filho, a partir dos investimentos sociais que incidem nesse pai para que ele produza um sujeito dócil, normalizado. O desejo não brota de um indivíduo; ele é, antes de tudo, devedor de "um campo social no qual o pai e o filho estão mergulhados" (DELEUZE; GUATTARI, 1972/2011, p. 363).

Por causa disso, Deleuze e Guattari (1972/2011, p. 134) afirmam que a triangulação edipiana "explode" por todos os cantos: as famílias "são cortadas por cortes que não são familiares"; o pai, a mãe e o eu "estão em combate e em contato direto com os elementos da situação histórica e política", a "relação com o não-familiar é sempre primeira" (DELEUZE; GUATTARI, 1972/2011, p. 473), e isso sob a forma mesma da sexualidade, da libido que investe esses atravessamentos do socius. As crianças não brincam apenas de "papai-mamãe", elas também brincam "de feiticeiro, de cowboy, de polícia e ladrão" (DELEUZE; GUATTARI, 1972/2011, p. 66). De maneira que, por trás do Édipo, o que se encontra é, fundamentalmente, uma relação com o fora, elementos da etnia, do gênero, da situação econômica, histórica, cultural etc. que são investidos pela libido enquanto libido sexual. "Sente-se tesão em meio a fluxos e seus cortes" (DELEUZE; GUATTARI, 1972/2011, p. 473).

Nesse sentido, Deleuze e Guattari (1972/2011, p. 158) apontam na direção de um sexual anedipiano, uma sexualidade que não dorme no quarto do Édipo. Essa dimensão de exterioridade foi como que exorcizada por Freud no curso de seu pensamento. Uma estranha espécie de recalcado que retorna, por assim dizer, na forma das "fantasias originárias", cuja origem é misteriosamente atribuída ao filogenético, sem nenhuma relação de causalidade a partir do complexo edipiano ou da história individual de um sujeito (DELEUZE; GUATTARI, 1972/2011, p. 127). Assim, ainda que Freud negligencie os cortes extrafamiliares que se intrometem nas maquinações de cuidado dos adultos sobre as crianças, Deleuze e Guattari (1972/2011) buscam relançar a importância desse elemento estrangeiro. E isso porque a mãe, por exemplo, também "funciona como outra coisa além de mãe e suscita na libido do filho todo um investimento social diferenciado" (DELEUZE; GUATTARI, 1972/2011, p. 471-472).

Levando em conta esse atravessamento do fora, um erro da psicanálise teria sido, portanto, o de "fazer como se as coisas começassem com o filho" (DELEUZE; GUATTARI, 1972/2011, p. 364), sendo que, antes disso, é um pai paranoico que edipianiza o pequeno sujeito humano. É esse pai que projeta a culpabilidade no 
filho prioritariamente, antes de ela ser um sentimento interior que brotaria da escolha de objeto parental feita de modo espontâneo pela criança. A ênfase excessiva num indivíduo ipsocentrado perderia de vista esses atravessamentos, de maneira que, para os autores, o abandono freudiano do tema da sedução, tema que envolve o outro real de forma radical, teria sido um passo infeliz em direção à reviravolta edipiana e idealista na psicanálise.

Tal reviravolta é marcada por uma ambiguidade na teorização freudiana entre o Édipo e as fantasias originárias, de modo que o autor parece não dar conta de articular mutuamente o complexo edipiano e a sexualidade infantil que havia inicialmente descoberto. A partir desse impasse, Freud acaba por soterrar "este mundo de produção selvagem e de desejo explosivo" (DELEUZE; GUATTARI, 1972/2011, p. 77) em favor da introdução de "um pouco de ordem, a ordem clássica do velho teatro grego", isto é, a narrativa edipiana.

Deleuze e Guattari entendem esse movimento como uma tentativa errônea de deduzir da proibição a natureza do proibido: já que isso é interditado, isso mesmo é que era desejado. “A lei nos diz: não desposarás tua mãe e não matarás teu pai. E nós, sujeitos dóceis, nos dizemos: então é isso que eu queria!" (DELEUZE; GUATTARI, 1972/2011, p. 156, grifo dos autores). No entanto, esse não é o motivo real do recalcamento. $\mathrm{O}$ desejo não é recalcado por ser desejo pela mãe e pela morte do pai: esta é apenas uma máscara secundária, posterior ao recalque, que produz aí um sujeito, mas é o sujeito, sobretudo, "que falta ao desejo, ou é ao desejo que falta sujeito fixo; só há sujeito fixo pela repressão" (DELEUZE; GUATTARI, 1972/2011, p. 43).

Desse modo, a máscara edipiana vem desfigurar e encobrir o potencial revolucionário do desejo: "Se o desejo é recalcado é porque toda posição de desejo, por menor que seja, pode pôr em questão a ordem estabelecida de uma sociedade [...] ele é perturbador; não há posição de máquina desejante que não leve setores sociais inteiros a explodir" (DELEUZE; GUATTARI, 1972/2011, p. 158). Algo que coloca radicalmente em questão as estruturas de exploração, sujeição e hierarquias de uma sociedade. Por causa disso, a representação do desejo por meio do Édipo acabou por esconder a produção desejante, as produções do inconsciente, isto é, a grande descoberta da psicanálise. Esta foi ocultada por um estranho tipo de idealismo: o inconsciente-fábrica, ateliê, usina, é substituído por um teatro antigo, palco, cena, encenação. As unidades de produção são trocadas, de modo que o inconsciente produtivo tornou-se um inconsciente que pode tão somente exprimir-se, representar-se, sob a forma do mito, da tragédia, do sonho etc. (DELEUZE; GUATTARI, 1972/2011, p. 40).

Nesse sentido, a esquizoanálise tenciona desenredar-se do "inconsciente expressivo edipiano" (DELEUZE; GUATTARI, 1972/2011, p. 135-136), artificial, repressivo, reprimido, sempre mediado pela família, "para atingir o inconsciente produtivo imediato". Isso porque, fazendo das relações familiares a mediação universal da infância, a produção do próprio inconsciente e os investimentos coletivos que nele operam restarão sempre desconhecidos. Afinal, o inconsciente é "órfão, assim como é anarquista e ateu" (DELEUZE; GUATTARI, 1972/2011, p. 411), ele "ignora as pessoas" (DELEUZE; GUATTARI, 1972/2011, p. 66). Por mais que o Édipo seja um verdadeiro organizador, ele não passa de uma "resistência que deve ser rompida" (DELEUZE; GUATTARI, 1972/2011, p. 415). Não há material inconsciente, há tão somente resistências e, depois, máquinas desejantes, isto é, as pulsões (DELEUZE; GUATTARI, 1972/2011, p. 53).

Assim, a questão do desejo é, para além de toda interpretação, um "como isso funciona" (DELEUZE; GUATTARI, 1972/2011, p. 149). Trata-se de descobrir, num sujeito, o funcionamento de suas máquinas desejantes infernais, isto é, seus circuitos pulsionais produtivos: "O que são as suas máquinas desejantes? o que você faz entrar nelas? o que você faz sair delas? [...] quais são os seus sexos não humanos?" (DELEUZE; GUATTARI, 1972/2011, p. 426). Para realizar essa tarefa, a esquizoanálise passa por uma destruição: "desfazer incansavelmente os eus e seus pressupostos" (p. 480), de maneira a "libertar as singularidades pré-pessoais que eles encerram e recalcam", fazendo correr "os fluxos que eles seriam capazes de emitir, de receber ou de interceptar, [...] bem abaixo das condições de identidade" (DELEUZE; GUATTARI, 1972/2011, p. 480-481).

Na medida em que o Édipo como dispositivo atua no sentido de fixar um sujeito pela repressão, é ele mesmo que produz as diferenciações simbólicas entre pai, mãe, filho, homem, mulher etc. e também o indiferenciado imaginário, o qual resultaria da rejeição dessas formas reificadas do simbólico. Dessa maneira, o desejo recebe, pela via edipiana, "um sujeito fixo, o eu especificado sob tal ou qual sexo, e objetos completos determinados como pessoas globais" (DELEUZE; GUATTARI, 1972/2011, p. 98). As coordenadas repressivas para a formação identitária do eu tornam-se as imagens parentais, papai-mamãe. A partir disso, essa estratégia familiar se prolonga num uso conjugal ou de aliança, em que "um regime de conjugação de pessoas substitui a conexão dos objetos parciais" (DELEUZE; GUATTARI, 1972/2011, p. 100).

A consequência desse dispositivo é que "as conexões de máquinas-órgãos próprias à produção desejante são substituídas por uma conjugação de pessoas sob as regras da reprodução familiar" (DELEUZE; GUATTARI, 1972/2011, p. 100). Com isso, os objetos parciais, que inicialmente deteriam sua própria autonomia nas conexões maquínicas, "parecem agora extraídos das pessoas", objetos globais, completos e determinados, "e não de fluxos não-pessoais que passam de uns a outros" (DELEUZE; GUATTARI, 1972/2011, p. 100). De maneira que o "desejo é apanhado numa armadilha, é especificado no conjunto molar unificado e identificado" (DELEUZE; GUATTARI, 1972/2011, p. 449). Conjuntos molares esses que devem ser destruídos, pois impedem de funcionar a máquina desejante, uma vez que esta, ao contrário, trabalha num regime de dispersão, nomadismo e plurivocidade dos elementos moleculares, muito além das condições repressivas de identidade. 
Isso na medida em que os "objetos parciais são as funções moleculares do inconsciente" (DELEUZE; GUATTARI, 1972/2011, p. 429). Dessa forma, tais funções moleculares não estão referidas a figuras edipianas globais; pelo contrário, elas conectam-se a fluxos que apontam para além de formas humanas. Assim, muito mais que representantes familiares ou parentais, a libido investe diretamente o social, aquilo que é "estranho, não-mãe, não-pai, não-família, índice daquilo que há de não humano no sexo, e sem o que a libido não montaria suas máquinas desejantes" (DELEUZE; GUATTARI, 1972/2011, p. 471, grifos do autor). Com isso, em seu projeto geral, Deleuze e Guattari buscam criticar as tradicionais separações dicotômicas entre indivíduo e sociedade, desejo e social, economia libidinal e economia política, uma vez que, para eles, a diferença entre esses termos não é de natureza, mas de regime.

\section{O Édipo como esquema narrativo em Jean Laplanche}

Jean Laplanche (2002/2015a), em sua retomada da descoberta freudiana, da sexualidade em sentido ampliado, enfatiza a primazia da alteridade na constituição psíquica do sujeito. Sua Teoria da Sedução Generalizada (TSG) é produto de uma reelaboração da teoria da sedução que foi abandonada por Freud em 1897. Ao investigar as causas do adoecimento das histéricas, o fundador da psicanálise levantou a hipótese de que a neurose seria gerada por um abuso sofrido na infância, uma sedução real por parte de um pai perverso, teoria que foi deixada de lado por uma série de dificuldades que carregava (cf. LAPLANCHE, 2002/2015a). Para Laplanche (2002/2015a, p. 106), Freud ainda não tinha os elementos necessários para compreender a teoria da sedução de forma expandida, que é o que encontramos na ideia laplancheana de uma sedução generalizada.

A TSG parte do pressuposto de que a constituição psíquica dos sujeitos se daria a partir de uma relação profundamente assimétrica, chamada por Laplanche (2002/2015a, p. 107) de "situação antropológica fundamental". De um lado, teríamos o adulto, ativo e com um aparelho psíquico já constituído, que, ao exercer o papel de cuidador, designaria (à revelia de si próprio) mensagens comprometidas por aspectos sexuais de seu inconsciente ao bebê. Este, do outro lado, receberia passivamente tudo aquilo que lhe é endereçado, na medida em que o pequeno sujeito humano não dispõe de um código inato para traduzir as mensagens recebidas, até mesmo por elas serem enigmáticas para o próprio adulto. Nascido em profundo desamparo ou desajuda (Hilflosigkeit), o bebê é incapaz de integrar e traduzir por completo tais mensagens, que seriam recebidas então como enigmáticas. Notamos aqui a presença invariável da alteridade no que Laplanche (1998) denominou de relação copernicana inicial, em que o sujeito gravita em torno do outro, de seus cuidados e de suas mensagens.

Com isso, o aparelho psíquico da criança será formado a partir de suas tentativas de tradução, do seu movimento de autoapropriação, de uma retomada ativa, num segundo tempo, daquilo que ela recebeu, originariamen- te, de maneira passiva. Das traduções feitas, sempre imperfeitas e malogradas, temos, de um lado, a formação da instância do Eu. Do outro lado, simultaneamente, a partir do que não pôde ser integrado no $\mathrm{Eu}$, forma-se o Isso. Algo que se torna a marca de uma alteridade inconsciente, um outro interno, com os restos intraduzíveis dessa operação tradutiva fundante, que comporiam o objeto-fonte da pulsão.

Bombardeado por tais mensagens enigmáticas, o pequeno sujeito humano é confrontado com uma carga de sentido sexual que excede suas capacidades de simbolização. Como consequência, esses significantes traumatizantes - que significam "para" alguém, mas sem encontrar vínculo a nenhum significado - sofrerão uma mutação, tornando-se significantes dessignificados. Esses serão os elementos que, para Laplanche (1993, p. 99), comporão o inconsciente, isto é, fragmentos de cenas, indícios, traços que perderam sua abertura referencial e sua abertura de comunicação, ou seja, estão fechados sobre si mesmos, o que lhes garante seu caráter enigmático, traumatizante, atacante. Por isso, até mesmo a ideia de "fantasias inconscientes" ainda guarda demasiada organização para descrever o que é o inconsciente, pois, numa cena da fantasia, já se trata de uma tradução feita.

Nesse sentido, Laplanche (1993, p. 99) sustenta que o inconsciente "não se reduz a uma linguagem", seu conteúdo não é linguageiro: as representações auditivas, verbais etc. só estão aí presentes a título de "coisa". Logo, as representações-coisa são significantes não-verbais que não remetem a um código linguístico, estão desinseridos dele, não respeitam a estrutura linguageira. A linguagem apenas "serve de passagem para outra coisa que não ela própria” (LAPLANCHE, 1993, p. 105), pois o inconsciente é o que, por definição, "não se deixa tecer" (LAPLANCHE, 1993, p. 105).

Esse inconsciente, que é enigmático para o adulto, faz ruído nas suas mensagens de cuidado sobre um pequeno sujeito humano, cuja origem é marcada por uma abertura radical. Devido a essa receptividade inicial passiva, o outro opera traumaticamente, engendrando um copernicanismo, um descentramento do sujeito. Apenas com a gênese do aparelho psíquico é que um esforço constante para o fechamento de uma tópica entraria em vigor, esforço este do sujeito para passar a operar de uma forma centrada sobre si mesmo, como que em um movimento ptolomaico, isto é, de recentramento, sob a égide do Eu. Esse movimento, entretanto, será sempre incompleto. A partir do momento em que concebemos a sexualidade como vinda de fora para dentro, implantada pelo outro, sempre haverá algo de estrangeiro, um corpo estranho-interno que parasita o sujeito.

Seguindo nessa esteira, com o intuito de reafirmar o Sexual como a descoberta freudiana por excelência, Laplanche (1997) realizou uma leitura crítica sobre a pulsão de morte, conceito que Freud delimitou em 1920, com o modelo do par antagonista de pulsões - Eros/pulsão de vida e pulsão de morte - em resposta à tendência conflituosa dos sujeitos de aspiração pela manutenção da vida e pela morte ao mesmo tempo. Enquanto Eros atuaria sob 
o princípio de homeostase, basicamente conservando a vida, atendendo ao princípio de prazer, a pulsão de morte atenderia a um mais além do princípio de prazer, assemelhando-se a uma força de desligamento, cuja tarefa seria retornar como organismo ao estado inanimado, inorgânico. De acordo com Laplanche (1997), a pulsão de morte aparece na obra freudiana para oferecer aquilo de mais disruptivo que não poderia ser abarcado em Eros.

É interessante notar que, para Freud, nesse momento, a sexualidade encontra-se essencialmente restrita à pulsão de vida, logo, apartada do aspecto desligante, disruptivo, das pulsões de morte. Com isso, a pulsão de morte seria marcada pela ausência do sexual, da sedução, da fantasia e do próprio processo de recalque. Esse ponto é amplamente criticado por Laplanche (1997, p. 95), que denuncia a redução do Sexual inicialmente descoberto por Freud, anárquico, demoníaco, a uma formação cada vez mais totalizante, originária, uma força natural de manutenção da vida.

O sexual, como o Eros freudiano, se transformou no amor totalitário, sintetizante. Quanto ao sexual desligado e desligador, precisamos de toda a nossa boa vontade para reconhecê-lo funcionando ali onde ele se esconde no sistema: precisamente sob a máscara da destrutividade.

Essa movimentação teórica acarreta, para Laplanche, um nítido comprometimento do pulsional como um todo: a pulsão (Trieb) acaba cedendo lugar ao instinto (Instinkt). A partir do pressuposto de que essas pulsões estariam presentes desde a origem do sujeito, isto é, um Eros e uma pulsão de morte originários, só seria possível pensar em um Eu que fosse também originário, o que excluiria a possibilidade de conceber o psiquismo como constituído a partir da alteridade, da relação adulto-infans, além de desconsiderar os aspectos mortíferos da sexualidade, suas formas mais desestruturadas e desestruturantes. Por isso, para Laplanche (1997), a pulsão sexual se dividiria em pulsão sexual de vida, isto é, pulsão sexual ligada ao eu (narcísica) ou aos objetos, e pulsão sexual de morte, pulsão sexual desligada.

Para Laplanche, com o desenvolvimento freudiano da teoria do narcisismo, pelo advento do eu como objeto do amor de si, de investimento objetal, a sexualidade "correu o risco de ser completamente açambarcada; correu-se o risco de não mais ver na sexualidade senão este aspecto ligado, investido, calmo, quiescente" (LAPLANCHE, 1988, p. 23). O eu seria responsável não apenas pela autoconservação, mas também pela sexualidade; esta foi subsumida pela pulsão de vida (LAPLANCHE, 1970/1985, p. 13). Porém, Eros difere profundamente da noção original de sexualidade, a pulsão sexual que, em 1905, Freud (1905/1996a, p. 152) definia como "a mais irrefreável de todas as pulsões", e que Laplanche (1970/1985, p. 109), tratando da pulsão sexual de morte, descreve como "Sedutora, traumatizante", "força demoníaca" (LAPLANCHE, 1970/1985, p. 112), com funcionamento "a-biológico, mortífero" (LAPLANCHE, 1970/1985, p. 124). É precisamente isso que Laplanche (1997, p. 95) vai enfatizar no surgimento e no funcionamento do Sexual:
A sedução, e o seu fundamento necessário, a prioridade do outro na constituição do sujeito sexual, é, da mesma forma, perfeitamente estranha a um sistema em que o adulto-objeto serve principalmente de ponto de fixação para movimentos instintuais, por natureza endógenos na criança.

O que significa que a pulsão sexual de morte assinala a presença de algo, na sexualidade, que não se deixa reduzir a formas ligantes e ligadas a objetos totais, a pessoas e/ou figuras sociais reificadas como papai-mamãe, tal como se formulam no complexo de Édipo. Esse elemento irredutível é propriamente o Sexual, que tudo pode colonizar: a sexualidade infantil perverso-polimorfa que persiste no inconsciente do adulto. É por isso que, em vez de referir-se ao triângulo edipiano, o que Laplanche (2002/2015a) propõe como indispensável, na fundação psíquica do sujeito, é a situação antropológica fundamental, isto é, a relação de assimetria nas relações de cuidado entre um adulto, assombrado pela presença de seu inconsciente sexual infantil, e uma criança. É esse inconsciente do adulto que inevitavelmente parasitará as relações de cuidado com um bebê. Por isso, "a relação adulto-infans me parece ultrapassar, em sua generalidade, em sua universalidade, a relação pais-criança" (LAPLANCHE, 2002/2015a, p. 107).

No entanto, em alguns pontos da teorização freudiana, é notável que o autor negligencia a sexualidade dos adultos nas relações de cuidado, como Laplanche (2003/2015b, p. 139) aponta em um comentário de Freud nas reuniões da Sociedade Psicanalítica de Viena. Essa omissão pode permitir leituras apressadas que culpabilizem a criança, como se nela houvesse uma sexualidade infantil inata, a fazer com que esses investimentos sexuais originários partissem de sua iniciativa. "No 'complexo de Édipo', o criminoso é Édipo, isto é, em última análise, a criança" (LAPLANCHE, 2003/2015b, p. 139). O que gera uma inversão decisiva e fatal no vetor da sedução originária.

Laplanche (2002/2015a) vem, justamente, reiterar a importância do papel do cuidador na sedução, em implantar e provocar no bebê uma sexualidade alteritária, sem pretender, com isso, situá-lo em uma posição perversa no sentido patológico, até porque, como já elucidado, esse processo se dá à revelia do próprio adulto. É preciso conceber, em um primeiro momento, a unilateralidade da sedução no sentido adulto-infans, de modo a evitar a noção de um inatismo da sexualidade no bebê. Só depois de ser convidada a traduzir tais mensagens enigmáticas e de receber ferramentas suficientes para fazê-lo é que podemos dizer que a criança passa a atuar de maneira mais ativa no processo de sedução.

Assim, criticando o equívoco em atribuir um voluntarismo edipiano espontâneo por parte do infans, Laplanche (2006/2015e, p. 285) afirma que o "iniciador de mensagens portadoras de sexualidade é mesmo o pai ou a mãe (ou o adulto). O incestuoso é potencialmente o adulto". Por causa disso, Laplanche (2006/2015e, p. 286) discorda de Freud quando este diz que o "complexo de Édipo" seria uma "situação por iniciativa da criança; o complexo de Édipo foi e continua sendo um mito, desde 
sua versão sofocliana até as versões freudianas e pós-freudianas". Até mesmo porque a "lei do complexo de Édipo não é universal, ainda que Freud pense isso. Ela não é a lei de Deus nem do pai todo-poderoso. Ela é contingente e [...] permeável" (LAPLANCHE, 2003/2015b, p. 151). Permeável porque deixa escapar o que diz respeito ao Sexual infantil, isto é, os elementos perverso-polimorfos que não dizem respeito a objetos totais, nem a figuras parentais socialmente reificadas, nem a ideais de realização genital, tampouco de reprodução sexuada. Assim, o Sexual é o que aponta justamente para uma sexualidade não edipiana.

Isso fica claro quando Laplanche (2003/2015b, p. 141) critica a antropologia estruturalista de Lévi-Strauss e seus usos dentro da psicanálise. Segundo Laplanche, teorias antropológicas como a de Lévi-Strauss, que estudam as estruturas sociais do parentesco, apenas levam em conta os dispositivos de aliança, de matrimônio, que proíbem certos casamentos e permitem outros. O que já é diferente de falar sobre o coito. E falar do coito é diferente, também, de falar sobre o Sexual infantil. Pois o estruturalismo lévi-straussiano "considera como paradigmático somente o incesto fraternal, precisamente no nível da troca possível de esposas, base da aliança, o que deixa de lado o interesse central da psicanálise, o incesto intergeracional, pai-filha ou filho, mãe-filha ou filho" (LAPLANCHE, 2003/2015b, p. 143).

Além disso, Laplanche (2003/2015b, p. 144) frisa o fato de que a lei francesa não proíbe o incesto sexual. Na França, só são proibidas "algumas alianças matrimoniais", não havendo "sanção além da impossibilidade ou nulidade". Se descoberto, na França, "esse casamento não tem nada de crime: ele é simplesmente anulado" (LAPLANCHE, 2003/2015b, p. 144). Por isso, o psicanalista afirma que, nas nossas sociedades, o que vemos é uma "degradação dos sistemas de parentesco e, na mesma medida, uma degradação da noção e da proibição do incesto" (LAPLANCHE, 2003/2015b, p. 149). Mas essa degradação não representa uma "via para a "liberdade sexual"'; antes, ela revela "um crime sexual muito mais radical, que o sistema parentesco/incesto se encarregava de controlar" (LAPLANCHE, 2003/2015b, p. 149), isto é, a sedução generalizada a que todo sujeito é submetido em sua infância por ser cuidado por um adulto.

Nesse sentido, os sistemas simbólicos de parentesco e de proibição do incesto viriam apenas recobrir, ligar o Sexual, isto é, uma sexualidade perverso-polimorfa que se transmite inevitavelmente nos cuidados originários dos adultos sobre os bebês. Assim, o Édipo seria apenas uma expressão dessas tentativas de recobrimento do Sexual: "Com o mito de Édipo, em Freud, qualquer ideia de promiscuidade e de perversão polimorfa originária se atenua" (LAPLANCHE, 2003/2015b, p. 147).

O complexo de Édipo acaba exercendo um papel organizador para a criança, na medida em que a ajuda a ligar e simbolizar o que lhe foi endereçado, propondo a ela uma forma narrativa para as mensagens sexuais. Forma essa que, apesar de transferir a culpa da sedução do adulto para a criança, "propõe uma versão bem mais suaviza- da, sexualmente falando" (LAPLANCHE, 2006/2015e, p. 286), para que o sujeito possa tratar o Sexual enigmático. Desse modo, torna-se mais fácil, para uma criança, lidar com esse Sexual a partir de uma referência às figuras parentais como objetos totais. Isso na medida em que ela poderia dizer, por exemplo, que seu sofrimento deriva de um ódio ao pai, ou que suas questões partem da influência amorosa de sua mãe.

Esse tratamento narrativo pela via do Édipo vem recobrir, então, o movimento muito mais cru da sedução generalizada, na qual são os adultos cuidadores que, por meio de suas ternuras "inocentes", implantam nos bebês algo de sua sexualidade inconsciente (cf. FREUD, 1905/1996a, p. 210-211). A partir disso, Laplanche (2006/2015e, p. 286) considera que esses "romances, esses roteiros variáveis entre os indivíduos, seriam, pois, da ordem de esquemas narrativos culturalmente transmitidos, e não, como gostaria a teoria clássica, da ordem de fantasias filogenéticas, pretensamente 'originárias"'. Por isso, sobre estruturas narrativas coletivas como o "complexo de Édipo", temos em Laplanche (2013/2015d, p. 205, grifos do autor) que:

[...] é preciso situar tais estruturas não do lado do recalcado, mas do lado do recalcante; não do lado do sexual primário, mas do lado do que vem ordená-lo e, finalmente, dessexualizá-lo, em nome da aliança, da procriação, etc. Nada de menos sexual (no sentido originário dos Três ensaios) que o mito de Édipo e a tragédia de Sófocles.

Seguindo nessa esteira, a "criança (e a cultura) não esperaram pela psicanálise para fazer tais traduções" (ANDRADE; MAIA, 2007, p. 74). Da mesma maneira que em Deleuze e Guattari (1972/2011), não é a psicanálise que inventa o Édipo; a ela "compete, portanto, ajudar a des-traduzir" (ANDRADE; MAIA, 2007, p. 74), já que interpretar no sentido de Édipo é ainda traduzir pela via do recalque.

\section{Um gênero edipiano}

Com Laplanche (2003/2015c), vemos que, dentro da sedução generalizada, as mensagens enigmáticas são também generificadas: elas promovem a designação de um gênero à criança, com todos os ruídos inconscientes que essa designação pode comportar. Afinal, naquilo que um infans é identificado "por" um adulto como menino ou menina, haverá também a intrusão de uma série de desejos inconscientes do cuidador nas mensagens endereçadas ao pequeno sujeito humano. Por exemplo, um pai pode "designar conscientemente o gênero masculino ao filho, mas pode ter esperado uma filha ou mesmo desejar inconscientemente penetrar uma filha" (LAPLANCHE, 2003/2015c, p. 169). Ou endereçar mensagens como "Você será a garota que eu nunca fui” (BUTLER, 2014, p. 127).

Tudo isso porque a designação de gênero é excessivamente enigmática para a criança: "O que meus pais querem de mim quando eles me chamam de uma garota?" (BUTLER, 2014, p. 130). Esses ruídos nas mensagens de gênero serão constantemente reiterados por toda a vida do sujeito, relançando-o numa tentativa eternamente falha de traduzir essas demandas inconscientes que lhe vêm do outro. Como forma de tratar esse enigma estra- 
nho-interno, a cultura, por meio do socius, propõe esquemas narrativos ou códigos tradutivos sob as roupagens do gênero. Assim, temos a tese de Laplanche (2003/2015c, p. 155): "O Sexual é o resíduo inconsciente do recalque-simbolização do gênero pelo sexo”.

Para o psicanalista, o gênero é plural; no entanto, na cultura ocidental, ele se apresenta normativamente de maneira dupla, com o binário masculino-feminino, a partir de uma tradução apoiada em uma anatomia dual. A nosso ver, essa anatomia em que o gênero se apoia parte de um modelo de sexualidade com fins reprodutivos. Tal modelo é transportado para um dispositivo de aliança baseado no casamento heterossexual, com fins pretensamente procriativos. Essas referências, no entanto, estão associadas a formas ligadas, objetos totais, figuras com o formato de pessoas: elas atuam no sentido de recalcar-simbolizar o Sexual. Porque, traduzida como "presença/ ausência do pênis, a diferença dos gêneros se afirmará, posteriormente, até mesmo no "complexo de Édipo"" (LAPLANCHE, 2006/2015e, p. 286).

Essa articulação binária dos gêneros tem, no Édipo, sua formalização, na medida em que a identificação-saldo do complexo, formando o Ideal do eu, pode estruturar um sujeito no sentido de "ser um homem como o pai", "querer um homem como o pai", "ser uma mulher como a mãe", "querer uma mulher como a mãe", entre várias outras combinações, isto é, formações essencialmente dessexualizadas, que tiram de cena o Sexual. Essas formas pessoais são aquelas que, em Deleuze e Guattari (1972/2011), assumem o formato molar de papai-mamãe, deixando de lado o que os autores chamam de "sexo não humano".

Assim, a partir do modelo binário de sexo, a "diversidade" de gêneros é traduzida em "diferença" sexual, que legitimará a noção normativa dual de masculino-feminino, promovendo, com isso, uma produção repressiva do desejo. Da mesma maneira, para Deleuze e Guattari (1972/2011, p. 390), existem "não um, nem mesmo dois, mas $n$ sexos". Isso é o que os esquizoanalistas chamam de uma representação molar, "antropomórfica" do sexo: o grande erro de supor que haveria apenas os sexos humanos: seja pela via de apenas um sexo (o falo, pela teoria lacaniana), seja pela via binária (macho-fêmea, homem-mulher). De modo que a principal diferença sexual não é entre os dois sexos humanos, mas entre os sexos humanos e os sexos não humanos, as verdadeiras máquinas desejantes com seus elementos maquínicos moleculares, "sem os quais não haveria nem sexo humano especificado nos grandes conjuntos, nem sexualidade humana capaz de investir esses conjuntos" (DELEUZE; GUATTARI, 1972/2011, p. 388).

Em nossa leitura, o "sexo não humano" pode ser, até certo ponto, aproximado ao Sexual infantil, traumaticamente molecular, que tudo pode colonizar. Afinal, como afirmam Deleuze e Guattari (1972/2011, p. 386), se a energia que move as máquinas desejantes é sempre a libido, então "a sexualidade está em toda parte", sem necessidade de metáforas. No entanto, pensando em uma articulação entre as contribuições de Laplanche e da esquizoanálise, lançamos a hipótese de que é o gênero bi- nário que serve de suporte para a repressão e o recalque do Sexual e do sexo não humano, por meio de uma tradução demasiado rígida para a diversidade.

Seguindo nessa esteira, o gênero, construído a partir do modelo da reprodução sexuada - isto é, de um sexo binário, que reparte os sujeitos entre homens e mulheres -, parece-nos depender do dispositivo de aliança heterossexual, referido a objetos totais, pessoas, sexos humanos, papai-mamãe, produzindo um esmagamento edipiano do desejo e do Sexual. Ao mesmo tempo, o gênero é responsável por reproduzir essa mesma estrutura para os pequenos sujeitos humanos. $\mathrm{O}$ gênero atua fixando o eu que será remetido às coordenadas edipianas. Porque, também para Deleuze e Guattari (1972/2011, p. 480), "nem o homem nem a mulher são, seguramente, personalidades bem definidas mas vibrações, fluxos, esquizas e "entrelaçamentos"'.

Nesse sentido, o eu irá remeter às coordenadas personológicas das quais ele resulta, e as pessoas, por sua vez, remeterão a coordenadas familiares, edipianizadas e, por isso, generificadas: homem, mulher, pai, mãe, filho, filha. Em suma, a sequência torna-se a seguinte: em sua formação edipiana, o eu é referido às pessoas; as pessoas são reendereçadas às configurações familiares; as famílias são formadas, tradicionalmente, a partir de uma divisão generificada heterossexual, e isso possibilita a perpetuação do Édipo com suas coordenadas sociais e seus efeitos repressivos.

Então, a nosso ver, o gênero binário, tal como o lemos a partir de Laplanche (2003/2015c), apresenta uma importância fundamental para a sedimentação do Édipo no socius. A fim de ilustrá-lo, tomemos a clássica leitura freudiana de que, no momento da dissolução do complexo edipiano nas meninas, bastaria a elas "assumir o lugar da mãe e adotar uma atitude feminina para com o pai" (FREUD, 1924/1996b, p. 198). Isso porque, em sua renúncia ao pênis que não lhe foi dado, alguma compensação teria de ocorrer, de maneira que o desejo da menina deslizaria, em uma equação simbólica, do pênis para um bebê, isto é, um filho do pai, ou, posteriormente, de um substituto seu. Esse desejo ficaria fortemente investido no inconsciente e ajudaria a "preparar a criatura do sexo feminino para seu papel posterior" (FREUD, 1924/1996b, p. 198), isto é, o que Freud considera como a maternidade.

Nesse ponto, apontamos para a negligência de Freud em relação aos aspectos sócio-históricos dessa construção. Em suas formulações, a menina espontaneamente desejaria o pênis que lhe falta e deslocaria esse desejo para um bebê do pai. No entanto, o psicanalista não leva em conta que são os cuidadores, isto é, o próprio socius, que fornecem às meninas, desde cedo, bonecas, bebês de brinquedo, aparatos domésticos etc. É isso que facilita, no caso das mulheres, a tradução do Sexual por meio dos arranjos binários de gênero (como se lhe dissessem: "falta-lhe alguma coisa, é isto que lhe falta, um bebê, uma boneca!"), produzindo o desejo como desejo de maternidade, o que implicará um casamento heterossexual a reproduzir a mesma estrutura edipiana da qual esse desejo se originou.

Fractal, Rev. Psicol., v. 32 - n. 2, p. 162-170, 2020 
A boneca como brinquedo dado prioritariamente às meninas participa de um código-esquema narrativo para a produção da mulher-mãe, algo que vem recalcar-simbolizar o Sexual por meio de uma repressão normativa edipiana. É nesse caminho que segue a afirmação de Deleuze e Guattari (1972/2011, p. 99): "Sair do Édipo, mas também reproduzi-lo, transmiti-lo antes do que morrer sozinho, incestuoso, homossexual e zumbi".

\section{Conclusões}

Tendo em mente o que expusemos até aqui, podemos pensar que há em Laplanche algumas leituras similares às propostas da esquizoanálise. Com isso, as teorizações laplancheanas nos parecem responder, em certa medida, às críticas de Deleuze e Guattari à psicanálise de sua época, a de meados do século XX. Dizemos "em certa medida" uma vez que existem pontos marcadamente divergentes entre as elaborações de tais autores. A noção de produção, base da teorização esquizoanalítica, por exemplo, não é incorporada por Laplanche, na medida em que o psicanalista não se propõe a fazer uma filosofia militante, tal como Deleuze e Guattari.

Se, por um lado, vemos Laplanche deixar de considerar, de certa forma, uma parte importante das contribuições ético-políticas da esquizoanálise, por outro, vemos Deleuze e Guattari negligenciando outras contribuições da psicanálise; é o caso do método analítico de interpretação que Laplanche desenvolve. Comentando um trabalho deleuziano, o psicanalista afirma: "Infelizmente, Deleuze não percebeu o que é a interpretação, a inovação propiciada pelo método [de interpretação, de leitura] analítico, em relação a toda hermenêutica" (LAPLANCHE, 1998, p. 281). Deleuze seria um bom "intérprete-filósofo", mas isso carrega suas limitações: ele nunca atenta para as possibilidades de um sentido inconsciente no texto, de uma inversão possível numa passagem, de falhas de um discurso que apontariam para a exigência do Sexual inconsciente.

É por isso que Laplanche (1997) tenta "fazer trabalhar" os textos de Freud, no intuito de localizar deslocamentos inconscientes que desviam a teoria de seu caminho analítico: o Sexual, sempre originado da relação do sujeito com o outro. Em sua leitura, Freud recorreria ao biológico, ao hereditário, ao instintivo, ao filogenético (ou até a uma mitofilogênese), diante de um impasse teórico, para evitar os elementos mais traumáticos, alteritários, da sexualidade. $\mathrm{Na}$ contramão dessas tendências, Laplanche procura retomar a prioridade do Sexual, algo que Deleuze e Guattari (1972/2011, p. 383) também fazem à sua maneira: para os esquizoanalistas, a libido é a "energia própria das máquinas desejantes", de maneira que suas transformações "nunca são dessexualizações nem sublimações".

Outro ponto de convergência entre Laplanche e a esquizoanálise é que ambos procuram respostas que passem - não pela falta, mas - pela via do excesso. Se, em Deleuze e Guattari (1972/2011) o inconsciente transborda de produção, de maquinações criativas, para Laplanche (2002/2015a), aquilo que faz trauma para uma criança, mas que também a transforma em um sujeito de desejo, é a presença infernal das mensagens sexuais com um ex- cesso de sentido que não é apreensível, simbolizável. De um lado, um desejo produtivo sempre aliado ao social; de outro, um estrangeiro-interno intraduzível.

Assim, em ambas as propostas encontramos a crítica a um indivíduo ipsocentrado e o atravessamento radical do outro e do socius na constituição subjetiva, seu descentramento radical por uma alteridade que lhe é anterior e que não deixa de intrometer-se no sujeito durante toda a sua vida, por exemplo, pelo recurso aos esquemas narrativos fornecidos pela cultura. Por isso, o desejo, as fantasias e os delírios não são meramente individuais. A um analista, portanto, caberia atentar também para a presença de elementos históricos, econômicos, raciais, culturais etc., como sinaliza a esquizoanálise em suas leituras de caso.

Vale reiterar, por fim, o aspecto não edipiano das propostas levantadas por Laplanche no que concerne à formação dos sujeitos: situação antropológica fundamental, e não complexo de Édipo; mensagens enigmáticas que implantam o Sexual, e não desejo pela mãe e pela morte do pai; ênfase no inconsciente infantil do adulto, e não numa escolha de objeto por iniciativa da criança. Nesse sentido, notamos como os mecanismos de gênero, a partir de Laplanche (2003/2015c), parecem atuar na direção de reproduzir as estruturas sociais edipianas, na medida em que, por um lado, o gênero depende delas e, por outro, estimula, induz sua reprodução. Essa série de reelaborações laplancheanas aponta, a nosso ver, para a possibilidade de uma psicanálise pós-edipiana ou, até mesmo, não edipiana.

\section{Informações sobre os autores: \\ Vinícius Moreira Lima \\ (iD) https://orcid.org/0000-0002-4253-8154 \\ (3) http://lattes.cnpq.br/2932481213382246}

Psicanalista. Mestrando em Estudos Psicanalíticos pelo Programa de Pós-Graduação em Psicologia da UFMG (2020-2022). Graduado em Psicologia pela UFMG. Pesquisador em psicanálise e teoria queer.

\section{Heloisa Moura Bedê}

(iD) https://orcid.org/0000-0001-7631-8224

(3) http://lattes.cnpq.br/3749889877832104

Psicanalista. Mestranda em Estudos Psicanalíticos pelo Programa de Pós-Graduação em Psicologia da UFMG (2020-2022). Graduada em Psicologia pela UFMG. Pesquisadora na área de psicanálise, histeria e feminino.

\section{Contribuição dos autores:}

Os autores colaboraram ao longo do processo, desde a elaboração até a revisão final do manuscrito. Ambos aprovaram o manuscrito final para publicação.

\section{Como citar este artigo:}

\section{ABNT}

LIMA, Vinícius Moreira; BEDÊ, Heloísa Moura. Para além do Édipo: entre Deleuze-Guattari e Laplanche. Fractal: Revista de Psicologia, Niterói, v. 32, n. 2, p. 162-170, maio./ago. 2020. https://doi.org/10.22409/1984-0292/v32i2/5762

APA

Lima, V. M., \& Bedê, H. M. (2020, Maio/Agosto). Para além do Édipo: entre Deleuze-Guattari e Laplanche. Fractal: Revista de Psicologia, 32(2), 162-170. doi: https://doi.org/10.22409/19840292/v32i2/5762 


\section{Copyright}

Copyright (C) 2020 Lima, V. M., \& Bedê, H. M. Este é um artigo em acesso aberto distribuído nos termos da Licença Creative Commons Atribuição que permite o uso irrestrito, a distribuição e reprodução em qualquer meio desde que o artigo original seja devidamente citado.

Copyright (C) 2020 Lima, V. M., \& Bedê, H. M. This is an Open Access article distributed under the terms of the Creative Commons Attribution License, which permits unrestricted use, distribution, and reproduction in any medium, provided the original article is properly cited.

\section{Referências}

ANDRADE, Fernando de; MAIA, Luís. Uma análise epistemológica da teoria da sedução generalizada: contribuições atuais para a cientificidade da psicanálise. Estudos de psicanálise, Belo Horizonte, n. 30, p. 65-76, 2007. Disponível em: $\quad$ http://pepsic.bvsalud.org/scielo.php?script=sci arttext\&pid=S0100-34372007000100009. Acesso em: 1 dez. 2016.

BUTLER, Judith. Seduction, gender, and the drive. In: FLETCHER, John; RAY, Nicholas (Org.). Seductions and enigmas: Laplanche, theory, culture. London: Lawrence \& Wishart, 2014. p. 118-133.

DELEUZE, Gilles. Cinco proposições sobre a psicanálise. In: . A ilha deserta e outros textos. São Paulo: Iluminuras, 2006. p. 345-352.

DELEUZE, Gilles; GUATTARI, Félix. $O$ anti-Édipo: capitalismo e esquizofrenia (1979). 2. ed. São Paulo: Editora 34, 2011.

FREUD, Sigmund. Três ensaios sobre a teoria da sexualidade (1905). In: SALOMÃO, Jayme (Org.). Obras Psicológicas Completas de Sigmund Freud. Rio de Janeiro: Imago, 1996a. v. 7, p. 119-229. Edição Standard Brasileira.

FREUD, Sigmund. A dissolução do complexo de Édipo (1924). In: SALOMÃO, Jayme (Org.). Obras Psicológicas Completas de Sigmund Freud. Rio de Janeiro: Imago, 1996b. v. 19, p. $193-$ 199. Edição Standard Brasileira.

LAPLANCHE, Jean. Vida e morte em psicanálise (1970). Porto Alegre: Artes Médicas, 1985.

LAPLANCHE, Jean. A pulsão de morte na teoria da pulsão sexual. In: WIDLOCHER, Daniel (Org.). A pulsão de morte. São Paulo: Escuta, 1988. p. 11-28.

LAPLANCHE, Jean. Problemáticas $V$ : a tina, a transcendência da transferência. São Paulo: Martins Fontes, 1993.

LAPLANCHE, Jean. Freud e a sexualidade: o desvio biologizante. Rio de Janeiro: J. Zahar, 1997.

LAPLANCHE, Jean. Problemáticas I: a angústia. 3. ed. São Paulo: Martins Fontes, 1998.

LAPLANCHE, Jean. A partir da situação antropológica fundamental (2002). In:__. Sexual: a sexualidade ampliada no sentido freudiano $\overline{2000-2006}$. Porto Alegre: Dublinense, 2015a. p. 103-115.

LAPLANCHE, Jean. O crime sexual (2003). In: Sexual: a sexualidade ampliada no sentido freudiano 2000 2006. Porto Alegre: Dublinense, 2015b. p. 137-153.
LAPLANCHE, Jean. O gênero, o sexo e o Sexual (2003). In: Sexual: a sexualidade ampliada no sentido freudiano 2000-2006. Porto Alegre: Dublinense, 2015c. p. 154-189.

LAPLANCHE, Jean. Três acepções da palavra "inconsciente" no âmbito da teoria da sedução generalizada (2003). In: . Sexual: a sexualidade ampliada no sentido freudiano 2000-2006. Porto Alegre: Dublinense, 2015d. p. 190-206.

LAPLANCHE, Jean. Castração e Édipo como códigos e esquemas narrativos (2006). In: Sexual: a sexualidade ampliada no sentido freudiano 2000-2006. Porto Alegre: Dublinense, 2015e. p. 280-287.

LAPLANCHE, Jean; PONTALIS, Jean-Bertrand. Vocabulário da psicanálise. 4. ed. São Paulo: Martins Fontes, 2016. 